\title{
Calcium intake in postmenopausal women: Evaluation and impact on diabetes
}

W . Grira; H.Kandara; H. Zoubeidi; E. Haouet; I.Kammoun; L. Ben Salem; C.Ben Slama

Department of Endocrinology and Metabolism, National Institute of Nutrition, Tunis, Tunisia

\section{Introduction}

Calcium intake is important to prevent osteoporosis in postmenopausal women. The objectives of our study were to evaluate the daily dietary calcium intake in postmenopausal Tunisian women, to compare diabetic and non-diabetic postmenopausal women in their calcium intake and finally to propose corrective interventions to promote calcium intake and minimize the complications of menopause.

\section{Subjects and methods:}

The study involved 73 postmenopausal Tunisian women (51 diabetic and 22 nondiabetic) aged on average 61 years.

Demographics and lifestyle were assessed with a questionnaire. Clinical and laboratory data were collected from medical records. Calcium intake was assessed by a food survey type "food story" and estimated by the BILNUT software.

\section{Results}

1. Main Features:

- Average age: $61,3 \pm 8,3$ years

- Mean BMI : $31,27 \pm 5,84 \mathrm{Kg} / \mathrm{m}^{2}$

- Percentage of obese (BMI>30kg/ $\left.\mathrm{m}^{2}\right): 57,5 \%$

- Mean HbA1c (in diabetic women):9,7 $\pm 2,8 \%$

- Mean calcemia: $2,22 \pm 0,11 \mathrm{mmol} / \mathrm{l}$

- Hypocalcemia $(\mathrm{Ca}<2,2 \mathrm{mmol} / \mathrm{l})$ : in $64,3 \%$ of patients

\section{Calcium intake:}

Average daily calcium intake: $723,8 \pm 260,13 \mathrm{mg} / \mathrm{d}$

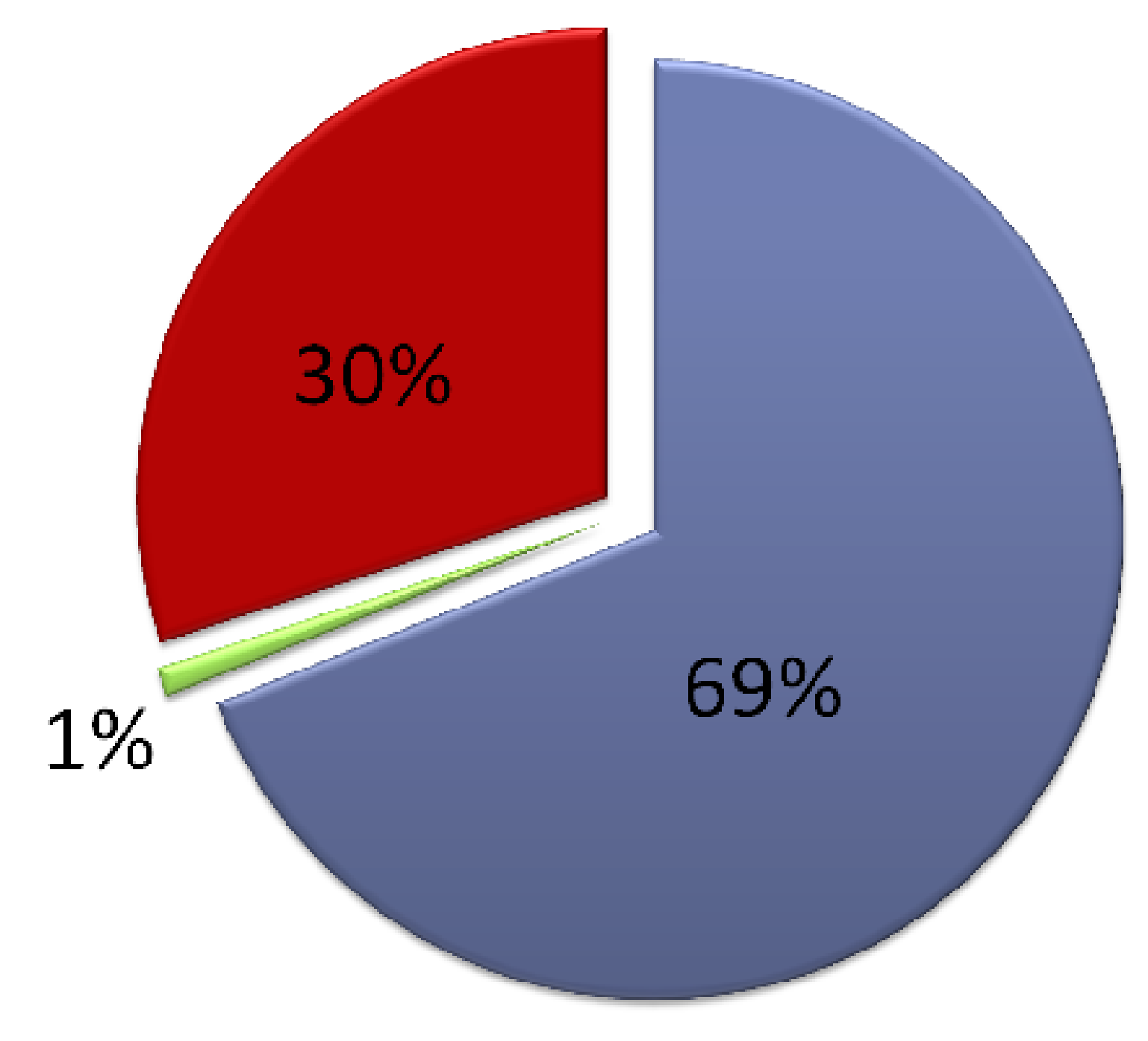

$$
\begin{aligned}
& \square<800 \mathrm{mg} / \mathrm{d} \\
& \square>1200 \mathrm{mg} / \mathrm{d} \\
& \square[800-1200 \mathrm{mg} / \mathrm{d}]
\end{aligned}
$$

\section{Comparison of calcium intake among menopausal women with and without diabetes:}
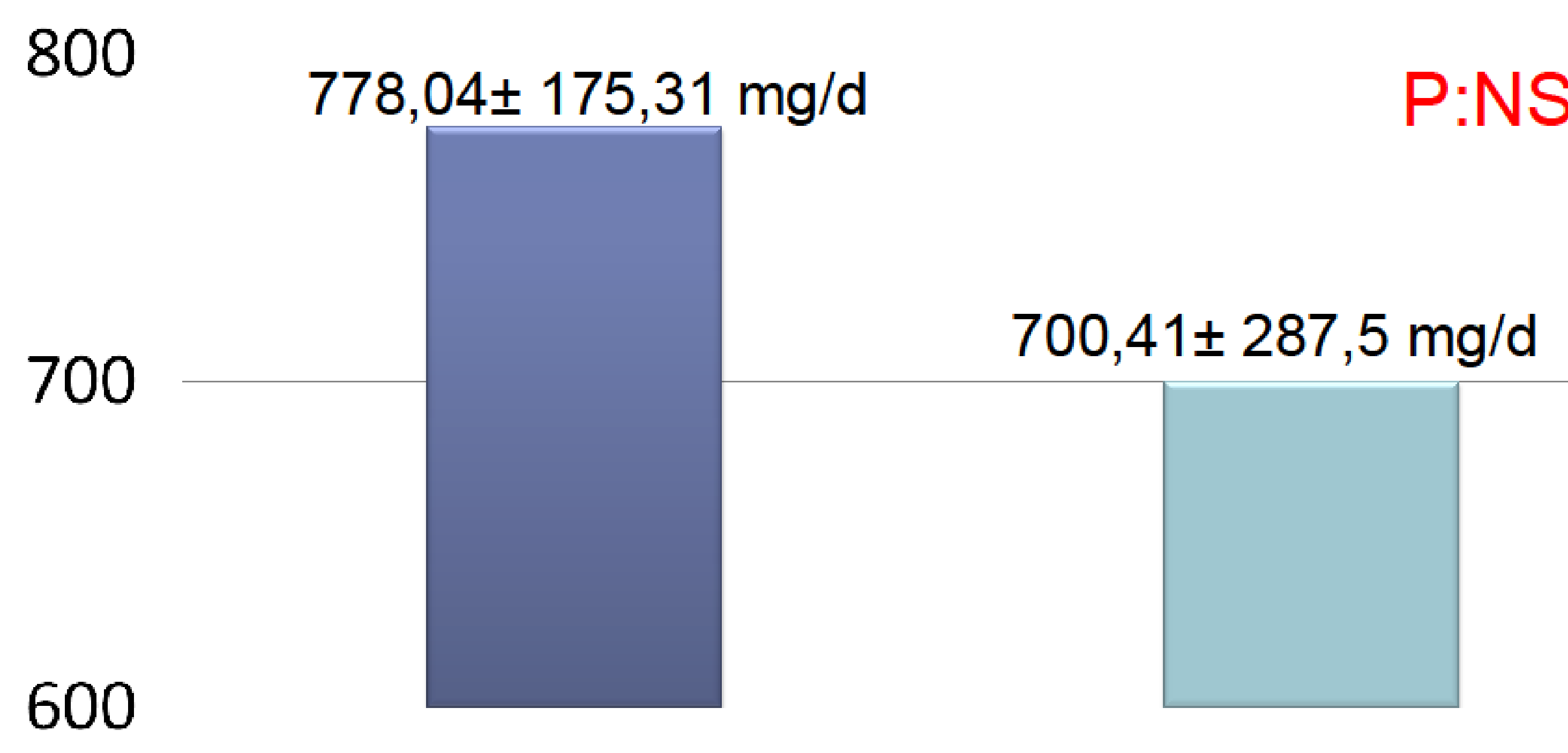

Nondiabetic

\section{Calcium intake based on parity :}

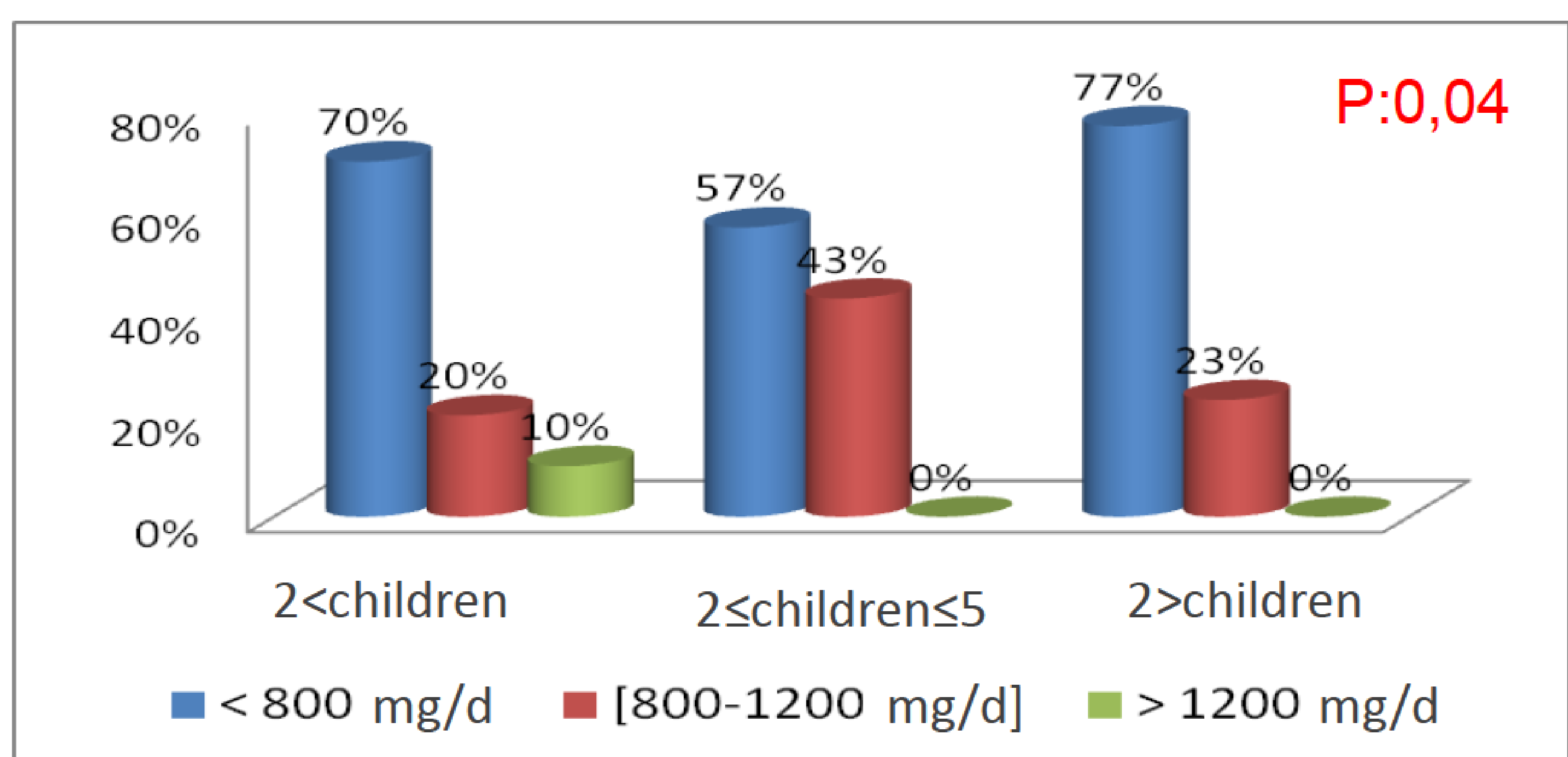

5. Calcium intake according to glycemic control in diabetic woman:

800

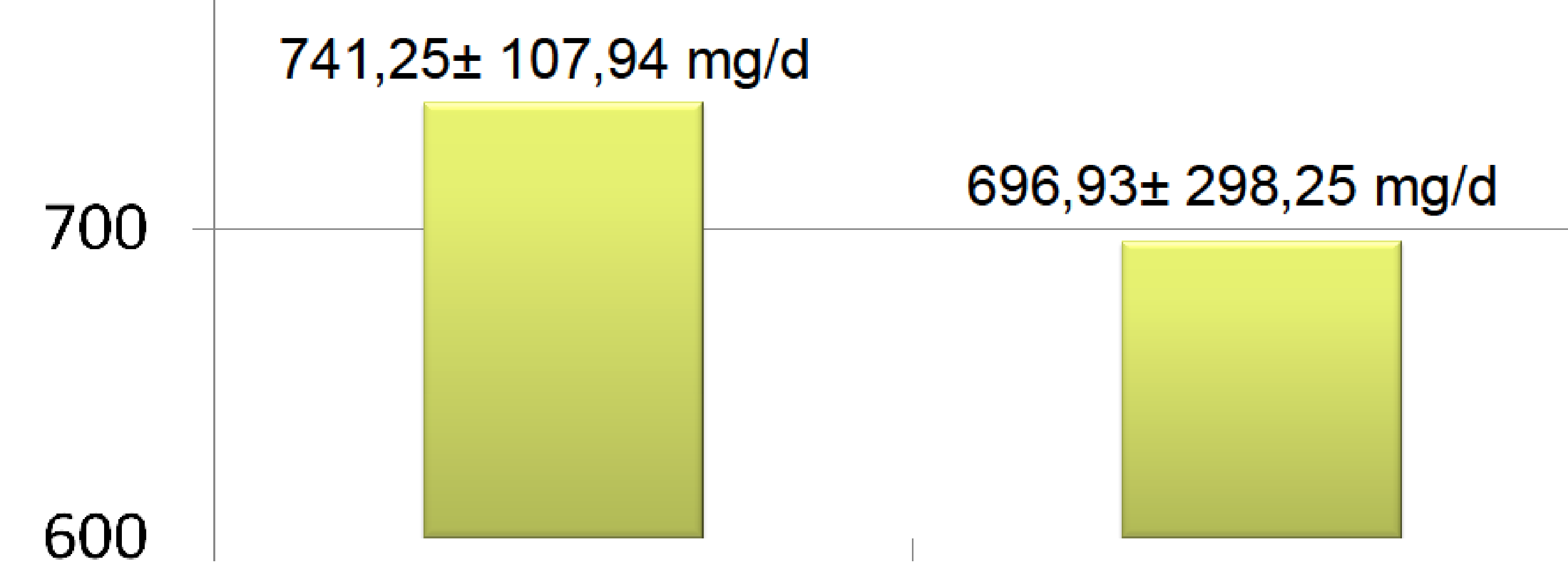

$\mathrm{HbA} 1 \mathrm{c}<7 \%$

\section{Discussion and Conclusion:}

The average calcium intake of our postmenopausal women is considered very low according to WHO. Only $1.3 \%$ of the patients had an intake deemed sufficient according to WHO. These alarming results are related to a multiparty and low educational context.

The average daily calcium intake in diabetic women was slightly lower than in non-diabetic, diabetic women with better glycemic control had calcium intake slightly higher than those HbA1c $>7 \%$ but the differences were not significant.

These results encourage us to develop educational messages about the importance of calcium intake in postmenopausal especially diabetic women. 